\title{
Numerical Modelling of Waves from the 1991 Cyclone in the Bay of Bengal (Bangladesh)
}

\author{
Mohammad Akhtaruzzaman Sarker \\ Water Business Line, Royal Haskoning DHV, Peterborough, United Kingdom
}

Email address:

zaman.sarker@rhdhv.com

To cite this article:

Mohammad Akhtaruzzaman Sarker. Numerical Modelling of Waves from the 1991 Cyclone in the Bay of Bengal (Bangladesh). American Journal of Water Science and Engineering. Vol. 4, No. 3, 2018, pp. 66-74. doi: 10.11648/j.ajwse.20180403.12

Received: July 30, 2018; Accepted: September 14, 2018; Published: October 17, 2018

\begin{abstract}
Cyclones cause significant loss of life and damage to properties, marine structures/facilities and ecosystems. Cyclone modelling results are used for deriving robust design conditions for coastal and marine structures and facilities. They are also used for emergency planning and decision-making to estimate potential loss of life, damage to properties and marine facilities and to develop rescue and mitigation measures and plan clean-up operations. Royal HaskoningDHV (hereafter RHDHV) has set up a regional wave model covering the Bay of Bengal and its wider surroundings to address these issues. A list of major cyclones in Bay of Bengal that have affected the Bangladeshi coastline since 1970 was initially identified. The 1991 Cyclone (22-30 April 1991) was found to be the second strongest cyclone affecting the coastal areas of Bangladesh since 1945 (after the Bhola Cyclone on 7-13 November 1970). This paper concentrates on the 1991 Cyclone to illustrate the use of numerical modelling to simulate waves generated by cyclones. The MIKE21 Spectral Wave Model of DHI was used in the study. Sample results of waves from the modelling study are presented in this paper for illustration purposes. The model could be used to simulate any cyclone originating in the Bay of Bengal and its surroundings. The methodology described in this paper for modelling cyclone waves in the Bay of Bengal could also be applied to simulate cyclones at other sites around the world.
\end{abstract}

Keywords: Numerical Modelling, Natural Hazards, Cyclones, Extreme Waves, Port Development, Bay of Bengal, 1991 Cyclone.

\section{Introduction}

Cyclones (also known as hurricanes or typhoons in different parts of the world) need some favourable conditions to form such as a) warm sea surface temperature b) large convective instability c) low level positive vorticity d) weak vertical wind shear of horizontal wind and e) Coriolis force.

Tropical cyclones are associated with warm and moist air and hence they form only over warm ocean waters near the equator. The warm and moist air rises causing an intense area of lower pressure beneath. Cooler air moves into the lower pressure area and becomes warm and moist and rises. When the warm and moist air rises, it cools down and forms clouds. The whole system of clouds and winds spins and grows and is fed by the ocean's heat and evaporated water. Cyclones require ocean temperatures of at least $26.5^{\circ} \mathrm{C}$ for their formation and growth through a relatively deep layer $(\sim 50 \mathrm{~m})$. Cyclones that form north of the equator spin counterclockwise whereas cyclones south of the equator spin clockwise due to the difference in Earth's rotation on its axis. Cyclones are, therefore, associated with steep pressure gradients and consequently generate strong winds and storm surges. The destruction from a tropical cyclone depends on its intensity, size and location.

During the last two centuries, cyclones have been responsible for the deaths of about 1.9 million people worldwide [1]. It is estimated that 10,000 people per year perish due to tropical cyclones [1]. Bangladesh is especially vulnerable to tropical cyclones with around 718,000 deaths from them in the past 50 years [2]. The deadliest tropical cyclone in Bangladesh was the 1970 Bhola Cyclone, which had a death toll of up to 500,000 [3]. At least 138,000 people were killed and as many as 10 million people were made homeless during the 1991 Cyclone in Bangladesh [4].

RHDHV has carried out literature search on cyclones in the Bay of Bengal from which 14 major cyclones have been 
identified since 1970. The 1991 Cyclone (22-30 April 1991) was found to be the second strongest cyclone affecting the coastal areas of Bangladesh (after the Bhola Cyclone on 7-13 November 1970). As less information is available on the Bhola Cyclone, this paper has concentrated on the 1991 event to illustrate the use of numerical modelling to simulate waves generated by cyclones.

A large wave model is required to simulate cyclone waves. Given the above risks, RHDHV has set up a regional wave model covering the Bay of Bengal and its wider surroundings to support their project work in the region. The MIKE21 Spectral Wave Model has been used in the study. Sample results of waves from the modelling studies are presented in this paper for illustration purposes only. The model could be used to simulate the passage of a cyclone anywhere within the Bay of Bengal. The methodology described in this paper for modelling cyclone waves in the Bay of Bengal could also be applied to simulate this type of events at other sites around the world.

\section{Major Cyclones in the Bay of Bengal}

The Bay of Bengal (BoB) is located in the north-east corner of the Indian Ocean and is surrounded by India, Bangladesh, Myanmar, Sri Lanka and the western part of Thailand. It is a semi-enclosed tropical basin which experiences seasonal changes in circulation and weather due to the monsoons. The Bay of Bengal is responsible for the formation of some of the strongest and deadliest tropical cyclones in the world. It is a potentially energetic region for the development of cyclonic storms accounting for about 7\% of the global annual total number of tropical storms [5].

The Bay of Bengal records a higher number of cyclones than the Arabian Sea. Most of the time sea surface temperature in the Bay of Bengal exceeds $28^{\circ}-30^{\circ} \mathrm{C}$ which is warmer than the Arabian Sea due to high stratification and less mixing. This is because the Bay of Bengal receives enormous volumes of fresh water from rains and has inflows from the world's largest river system - Ganges, Brahmaputra and Meghna. Since fresh water is lighter than the salty waters in the Bay of Bengal, it forms a thin layer on the surface. This thin layer of fresh water is heated more easily than the extremely salty waters of the Arabian Sea and these higher sea surface temperatures create favourable conditions for convection in the overlying atmosphere. Furthermore, the remnant depressions of the typhoons that form over the West Pacific Ocean sometimes cross into the Bay of Bengal from South China Sea with minimal weakening. The reason is that the Kra Isthmus which connects Malaysia to rest of Asia is narrow and the landmass does not have a significant influence on the strength of tropical cyclones travelling into the Bay of Bengal. Finally, the smaller difference in wind speed with respect to altitude (weak vertical wind shear of horizontal wind) over the Bay of Bengal creates a favourable condition for the formation of cyclones.

Historical cyclone data for the Bay of Bengal by monthly occurrence between 1877 and 2010 were obtained by RHDHV from the Indian Meteorological Department [6] for a project in the east coast of India. The monthly distribution of these events is presented in Table 1.

Table 1. Monthly occurrence of historical cyclones in the Bay of Bengal during 1877-2010 [6].

\begin{tabular}{|c|c|c|c|c|c|c|c|c|c|c|c|}
\hline Jan & Feb & Mar & Apr & May & Jun & Jul & Aug & Sep & Oct & \begin{tabular}{|l} 
Nov \\
\end{tabular} & Dec \\
\hline 7 & 2 & 2 & 23 & 75 & 104 & 142 & 177 & 158 & 156 & 109 & 38 \\
\hline
\end{tabular}

A total of 14 major cyclones have occurred in the Bay of Bengal since 1970 and these are shown in Table 2.

Table 2. Selected major Cyclones in the Bay of Bengal since 1970.

\begin{tabular}{|c|c|c|c|c|c|c|c|}
\hline \multirow[b]{2}{*}{ No. } & \multirow[b]{2}{*}{ Year } & \multirow[b]{2}{*}{ Codes \& Names } & \multicolumn{2}{|l|}{ Time \& Date } & \multirow{2}{*}{$\begin{array}{l}\text { Maximum 1-minute } \\
\text { mean sustained } \\
\text { wind speeds (knots) }\end{array}$} & \multirow{2}{*}{$\begin{array}{l}\text { Minimum } \\
\text { central } \\
\text { pressure (hPa) }\end{array}$} & \multirow{2}{*}{$\begin{array}{l}\text { Radius of } \\
\text { maximum wind } \\
\text { speeds }(\mathrm{nm})\end{array}$} \\
\hline & & & Start & End & & & \\
\hline 1 & 1970 & Bhola Cyclone & 07/11/1970 18:00 & 13/11/1970 00:00 & 130 & 960 & N/A \\
\hline 2 & 1972 & $\mathrm{TC} 14 \mathrm{~B}$ & 15/11/1972 06:00 & 23/11/1972 00:00 & 90 & N/A & N/A \\
\hline 3 & 1975 & TC 02B & 01/05/1975 00:00 & 11/05/1975 12:00 & 95 & N/A & N/A \\
\hline 4 & 1977 & TC 05B & 09/11/1977 00:00 & 23/11/1977 00:00 & 110 & N/A & N/A \\
\hline 5 & 1977 & TC 06B & 14/11/1977 00:00 & 20/11/1977 12:00 & 110 & N/A & N/A \\
\hline 6 & 1982 & TC $01 \mathrm{~B}$ & 30/04/1982 06:00 & 05/05/1982 12:00 & 120 & $\mathrm{~N} / \mathrm{A}$ & $\mathrm{N} / \mathrm{A}$ \\
\hline 7 & 1988 & TC 04B & 21/11/1988 18:00 & 30/11/1988 00:00 & 110 & N/A & N/A \\
\hline 8 & 1990 & TC 02B & 03/05/1990 12:00 & 11/05/1990 06:00 & 125 & N/A & N/A \\
\hline 9 & 1991 & TC 02B (BoB 01) & $22 / 04 / 1991$ 18:00 & 30/04/1991 18:00 & 140 & N/A & N/A \\
\hline 10 & 1992 & BoB-8 & 16/11/1992 06:00 & 21/11/1992 18:00 & 112 & 952 & N/A \\
\hline 11 & 1994 & TC 02B & 26/04/1994 18:00 & 03/05/1994 12:00 & 125 & N/A & N/A \\
\hline 12 & 1999 & TC $05 \mathrm{~B}$ & 25/10/1999 00:00 & 03/11/1999 06:00 & 140 & N/A & N/A \\
\hline 13 & 2013 & TC 02B (Phailin) & 07/10/2013 12:00 & $13 / 10 / 201312: 00$ & 140 & 918 & 10 \\
\hline 14 & 2014 & TC 03B (Hudhud) & 06/10/2014 06:00 & $13 / 10 / 201412: 00$ & 115 & 937 & 10,15 \\
\hline
\end{tabular}

Data for Cyclone 1 was obtained from Wikipedia [3]. Data for Cyclone 10 was obtained from IMD [6] and the 3-minute mean wind speed of 102 knots was converted to 1-minute mean of 112 knots using the method described in [7]. Data for the remaining cyclones were obtained from the Joint Typhoon Warning Center (JTWC), USA [8]. The JTWC archived cyclone data contains 6 hourly information including date and time, track (path), maximum sustained 
wind speeds, radius of maximum sustained wind speeds and the minimum central pressures.

The Bay of Bengal is vulnerable to cyclones predominantly in the pre-monsoon months of April-May (early summer) and the post-monsoon months of OctoberDecember (late rainy season). The monsoon season is from June to September when the formation of cyclones is less likely. Cyclones of the pre-monsoon and post-monsoon seasons are the most destructive due to great instability of the atmosphere and the weak vertical winds. They generally form over the Andaman Sea or south-east of the Bay of Bengal. They initially move to west or north-west and then to the north and finally to north-east across Bangladesh.

Over the last 50 years (1960-2007) around 18 severe cyclones have hit the coast of Bangladesh causing enormous disruptions, damages and a remarkable number of deaths. The deadliest events include the 1970 Bhola Cyclone, 1991 Tropical Cyclone, Orissa Cyclone (1999) and the Cyclone Sidr (2007).

\section{The 1991 Cyclone in Bangladesh}

\subsection{Formation of the 1991 Cyclone}

The 1991 Tropical Cyclone was classified as Super Cyclonic Storm (BOB 01) by IMD [6] and as Category 5 Tropical Cyclone (02B) by JTWC [8]. The cyclone formed in the morning at 09:00 BST (Bangladesh Standard Time) on 25 April 1991 as a depression at $10.0^{\circ} \mathrm{N}$ and $89.0^{\circ} \mathrm{E}$. It intensified into a deep depression in the same evening and then very quickly turned into a cyclonic storm at midnight on 25 April with a maximum sustained wind speed of $65-87$ $\mathrm{km} / \mathrm{h}$ and a central pressure of $996 \mathrm{hPa}$. It retained this intensity until 15:00 BST of 27 April when it was found to have developed into a severe cyclonic storm with maximum wind speed of $90-115 \mathrm{~km} / \mathrm{h}$ and central pressure of $990 \mathrm{hPa}$. At midnight of 27 April it turned into a very severe cyclonic storm with wind speed more than $130 \mathrm{~km} / \mathrm{h}$. The cyclone started moving in a north-easterly direction on 28 April and finally it crossed the coast north of Chittagong Port in the early morning (0400 BST) of 30 April as a super cyclonic storm. The maximum wind speed observed at Sandwip Island was $235 \mathrm{~km} / \mathrm{h}$ and the central pressure was $920 \mathrm{hPa}$ with a pressure drop of $80 \mathrm{hPa}$. The actual wind speed there was higher as the wind measuring device was blown away after this speed was recorded. The low pressure in conjunction with the full moon was sufficient to raise tidal levels to the highest of the normal range. In addition, landfall occurred over high tide. Much of the above information was obtained from [9] and [11].

\subsection{Damages from the 1991 Cyclone}

The 1991 Cyclone killed over 138,000 people and an estimated 13.4 million people were affected. Around one million homes were destroyed leaving 10 million people homeless. The coastline was devastated due to the high winds and the storm surge which peaked over the high tide period. A concrete levee near the mouth of the Karnaphuli River in Patenga was washed away by the cyclone. A 100-ton crane from the Port of Chittagong was uprooted and smashed on the Karnaphuli River Bridge breaking it into two parts. The Bangladesh Navy and Bangladesh Air Force bases were heavily affected with heavy damages to the ships and fighter planes. A large number of boats and smaller ships ran aground. Land erosion resulted in farmers losing their land and crops were washed away. The salt industry and shrimp farms were left devastated. Within Bangladesh, the damage from the cyclone was estimated at $\$ 1.5$ billion (1991).

Continuous rainfall and gusty winds affected Tripura and Mizoram states of north-east India causing some loss of life, destroying many houses and disrupting telecommunication systems.

The above information was obtained from Wikipedia [4].

\subsection{Track and Data of the 1991 Cyclone}

The track (route) of the 1991 Cyclone was obtained from [4] and is shown in Figure 1. The cyclone data was obtained from JTWC [8]. The JTWC archived cyclone data contains 6 hourly information including date and time, track (path), maximum sustained wind speeds (1-minute), radius of maximum sustained wind speeds and the minimum central pressures. However, for the 1991 Cyclone, the JTWC website does not provide the radius of maximum sustained wind speeds and the minimum central pressures. Therefore, these parameters were estimated from the relationship between maximum wind speed and radius of maximum wind derived from more recent major cyclones in the Bay of Bengal for which complete information was available from the JTWC website. Similarly, these events were used to estimate the minimum central pressure based on a relationship between maximum wind speed and the minimum central pressures. Data on the 1991 Cyclone is provided in Table 3. It should be noted that the maximum wind speeds in Table 3 are now 1hourly mean converted from the 1-minute mean of the JTWC wind data using the methodology described in [7].

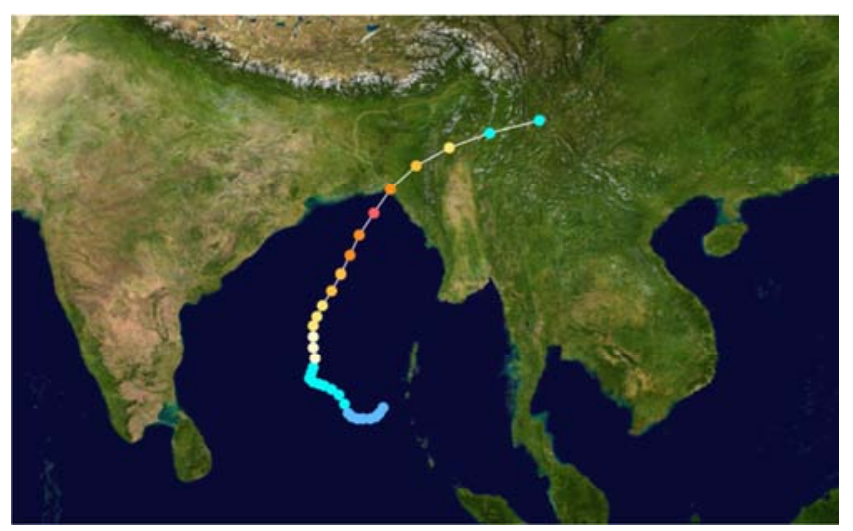

Figure 1. Track and intensity of the 1991 Cyclone [4]. 
Table 3. Track and Data of the 1991 Cyclone [8].

\begin{tabular}{|c|c|c|c|c|c|c|c|c|}
\hline Date & $\begin{array}{l}\text { Time } \\
\text { (UTC) }\end{array}$ & $\begin{array}{l}\text { Time } \\
\text { (hour) }\end{array}$ & $\begin{array}{l}\text { Longitude } \\
\left({ }^{\circ} \mathbf{E}\right)\end{array}$ & $\begin{array}{l}\text { Latitude } \\
\left({ }^{\circ} \mathrm{N}\right)\end{array}$ & $\begin{array}{l}\text { Radius of max } \\
\text { winds }(\mathbf{k m})\end{array}$ & $\begin{array}{l}\text { Max 1-hourly } \\
\text { wind speeds }(\mathrm{m} / \mathrm{s})\end{array}$ & $\begin{array}{l}\text { Central pressure } \\
(\mathrm{hPa})\end{array}$ & $\begin{array}{l}\text { Constant neutral } \\
\text { pressure }(\mathrm{hPa})\end{array}$ \\
\hline $22 / 04 / 1991$ & 1800 & 0 & 91.2 & 10.0 & 63.0 & 8.29 & 1041.9 & 1013 \\
\hline 23/04/1991 & 0000 & 6 & 91.0 & 9.7 & 63.0 & 8.29 & 1041.9 & 1013 \\
\hline$"$ & 0600 & 12 & 90.8 & 9.5 & 63.0 & 8.29 & 1041.9 & 1013 \\
\hline$"$ & 1200 & 18 & 90.5 & 9.4 & 61.1 & 10.36 & 1036.7 & 1013 \\
\hline$"$ & 1800 & 24 & 90.1 & 9.4 & 61.1 & 10.36 & 1036.7 & 1013 \\
\hline 24/04/1991 & 0000 & 30 & 89.8 & 9.4 & 61.1 & 10.36 & 1036.7 & 1013 \\
\hline " & 0600 & 36 & 89.5 & 9.5 & 59.3 & 12.44 & 1031.6 & 1013 \\
\hline " & 1200 & 42 & 89.3 & 9.7 & 59.3 & 12.44 & 1031.6 & 1013 \\
\hline$"$ & 1800 & 48 & 89.1 & 10.2 & 57.4 & 14.51 & 1026.4 & 1013 \\
\hline 25/04/1991 & 0000 & 54 & 88.8 & 10.7 & 57.4 & 14.51 & 1026.4 & 1013 \\
\hline " & 0600 & 60 & 88.4 & 11.0 & 55.6 & 16.58 & 1021.2 & 1013 \\
\hline$"$ & 1200 & 66 & 88.0 & 11.2 & 55.6 & 16.58 & 1021.2 & 1013 \\
\hline$"$ & 1800 & 72 & 87.7 & 11.3 & 53.7 & 18.65 & 1016.0 & 1013 \\
\hline 26/04/1991 & 0000 & 78 & 87.4 & 11.4 & 51.9 & 20.73 & 1010.8 & 1013 \\
\hline " & 0600 & 84 & 87.2 & 11.6 & 51.9 & 20.73 & 1010.8 & 1013 \\
\hline$"$ & 1200 & 90 & 87.3 & 11.9 & 50.0 & 22.80 & 1005.6 & 1013 \\
\hline$"$ & 1800 & 96 & 87.4 & 12.2 & 48.2 & 24.87 & 1000.4 & 1013 \\
\hline 27/04/1991 & 0000 & 102 & 87.5 & 12.7 & 46.3 & 26.94 & 995.2 & 1013 \\
\hline " & 0600 & 108 & 87.4 & 13.3 & 42.6 & 31.09 & 984.8 & 1013 \\
\hline$"$ & 1200 & 114 & 87.4 & 13.9 & 40.7 & 33.16 & 979.7 & 1013 \\
\hline$"$ & 1800 & 120 & 87.4 & 14.5 & 38.9 & 35.23 & 974.5 & 1013 \\
\hline 28/04/1991 & 0000 & 126 & 87.6 & 15 & 37.0 & 37.31 & 969.3 & 1013 \\
\hline " & 0600 & 132 & 87.9 & 15.6 & 35.2 & 39.38 & 964.1 & 1013 \\
\hline$"$ & 1200 & 138 & 88.4 & 16.4 & 33.3 & 41.45 & 958.9 & 1013 \\
\hline " & 1800 & 144 & 88.9 & 17.3 & 29.6 & 45.60 & 948.5 & 1013 \\
\hline 29/04/1991 & 0000 & 150 & 89.4 & 18.3 & 25.9 & 49.74 & 938.1 & 1013 \\
\hline " & 0600 & 156 & 89.9 & 19.4 & 22.2 & 53.89 & 927.7 & 1013 \\
\hline$"$ & 1200 & 162 & 90.7 & 20.6 & 18.5 & 58.03 & 917.4 & 1013 \\
\hline$"$ & 1800 & 168 & 91.6 & 21.9 & 20.4 & 55.96 & 922.6 & 1013 \\
\hline 30/04/1991 & 0000 & 174 & 93 & 23.2 & 29.6 & 45.60 & 948.5 & 1013 \\
\hline$"$ & 0600 & 180 & 94.8 & 24.2 & 38.9 & 35.23 & 974.5 & 1013 \\
\hline " & 1200 & 186 & 97 & 25 & 48.2 & 24.87 & 1000.4 & 1013 \\
\hline " & 1800 & 192 & 99.7 & 25.7 & 55.6 & 16.58 & 1021.2 & 1013 \\
\hline
\end{tabular}

\section{Wind and Pressure Fields Generation}

The MIKE21 Cyclone Wind Generation Tool of DHI [12] was used to generate the cyclonic wind and pressure fields. The tool allows users to compute wind and pressure data due to tropical cyclones. Several cyclone parametric models are included in the tool such as Young and Sobey model (1981), Holland - single vortex model (1981), Holland - double vortex model (1980) and Rankine vortex model. All the six input parameters required by the Young and Sobey model (i.e. time, track, radius of maximum wind speed, maximum wind speed, central pressure and neutral pressure) were available for the study and this was, therefore, used to generate the cyclonic wind and pressure fields. The other models require some additional parameters (such as Holland parameter B and Rankine parameter $\mathrm{X}$ ) that need to be calculated using empirical relationships. This adds further uncertainty to the generated wind and pressure fields. Therefore, the other models were not used for the study. Figure 2 shows an example of wind and pressure fields from the 1991 Cyclone on 29/04/1991 11:00 when it generated the maximum wave heights. These wind and pressure fields were used to drive the cyclone wave and surge models described later.

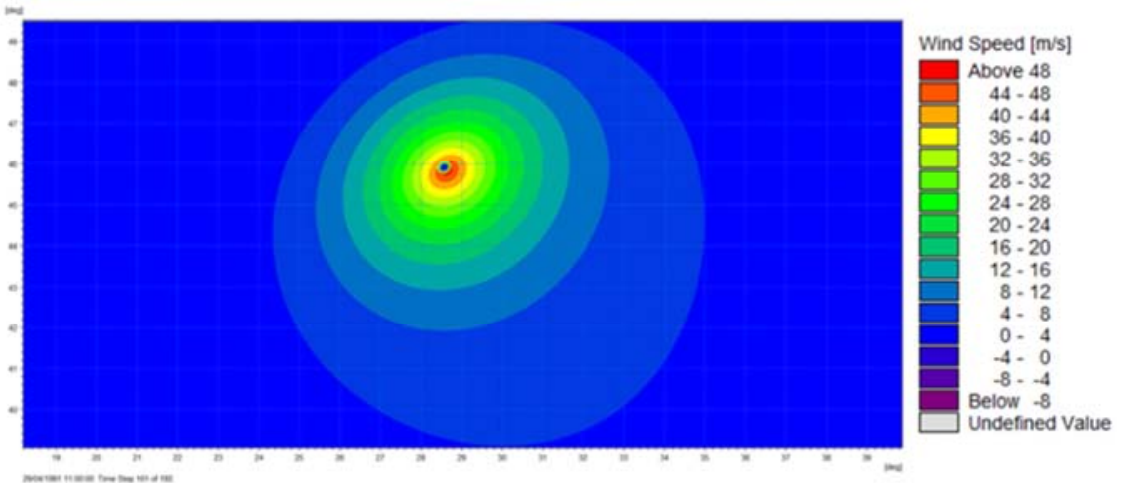

a. Wind fields of the 1991 Cyclone. 


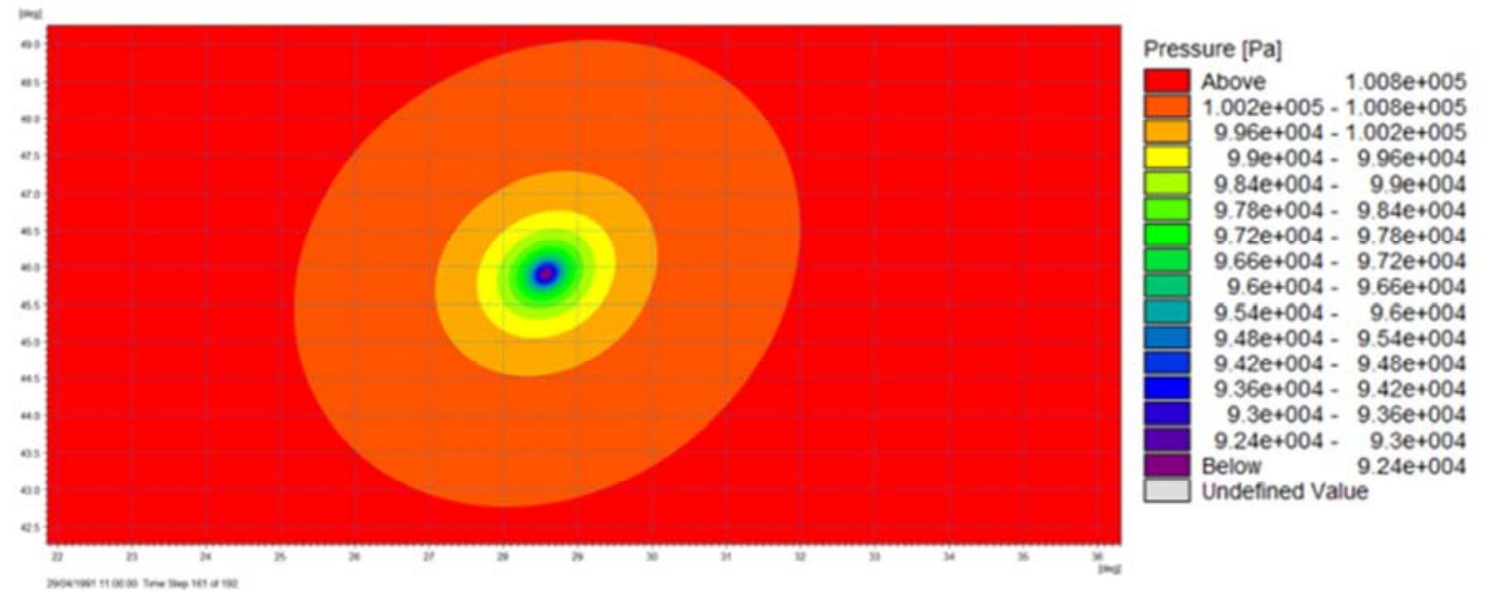

b. Pressure fields of the 1991 Cyclone

Figure 2. Wind and pressure fields of the 1991 Cyclone on 29/04/1991 11:00:00.

\section{Bay of Bengal Regional Wave Model Set Up by RHDHV}

RHDHV has set up a two-dimensional Regional Wave Model for the Bay of Bengal using the MIKE21 Spectral Wave Model of DHI [13]. The model considers various physical phenomena, for example, wave growth by the action of wind, non-linear wave-wave interaction, dissipation due to white-capping, dissipation due to bottom friction, dissipation due to depth-induced wave breaking, wave diffraction, wave refraction, wave shoaling and wave-current interaction. The fully spectral formulation of the model is based on the wave action conservation equation, where the directionalfrequency wave action spectrum is the dependent variable.

The regional wave model covers the coastlines of six countries - India, Sri Lanka, Bangladesh, Myanmar, Malaysia and Indonesia (see Figure 3). An unstructured flexible mesh (with variable cell sizes) was used and model bathymetry (as shown in Figure 3) was obtained from the CMap Global Database [14].

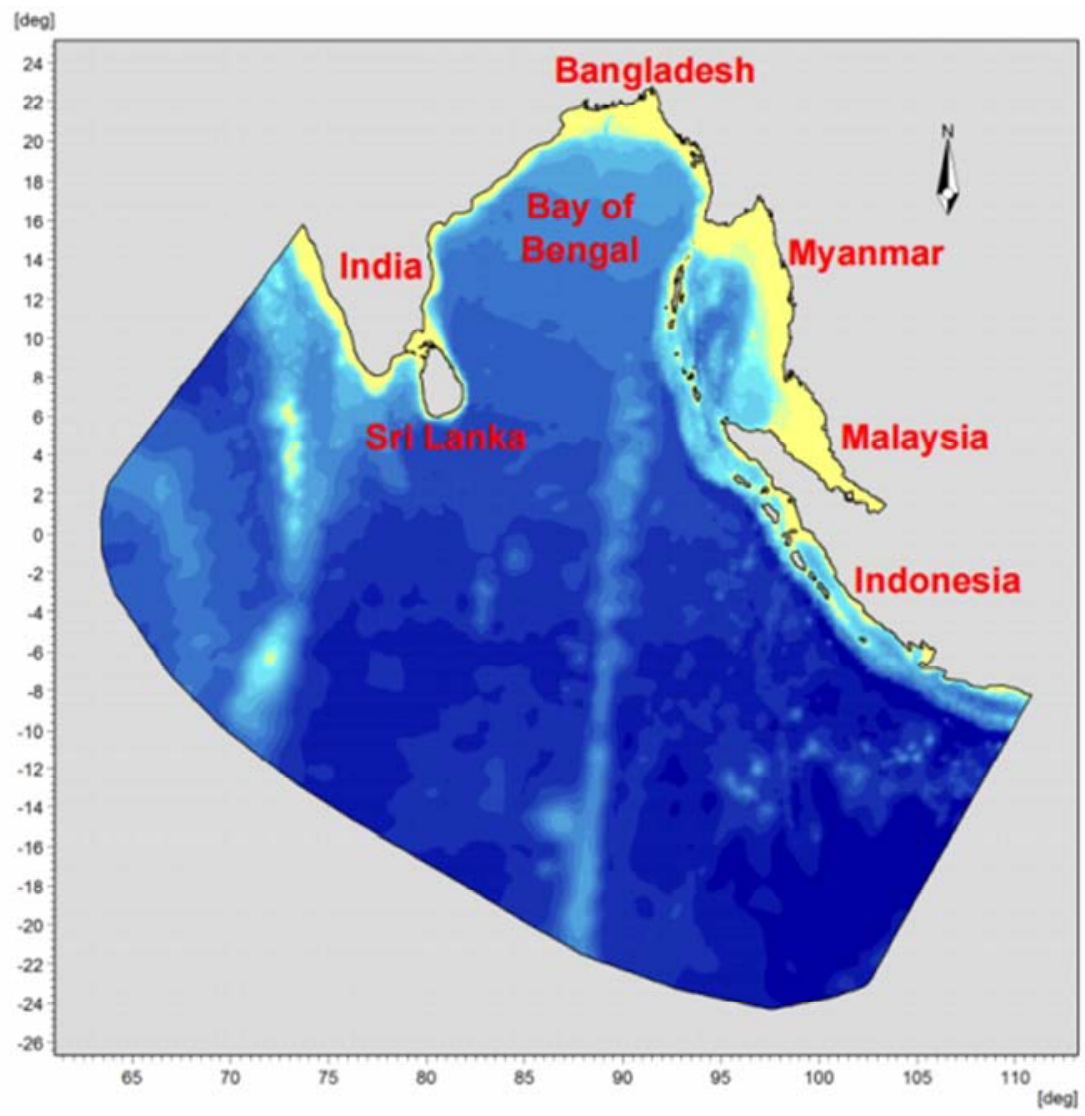

Bathymetry [mCD]

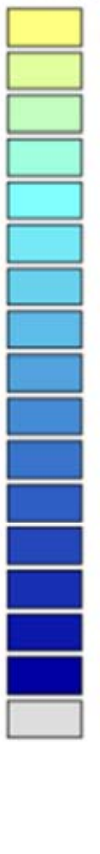

Above -100

$-200--100$

$-300--200$

$-400--300$

$-500--400$

$-1000--500$

$-1500--1000$

$-2000--1500$

$-2500--2000$

$-3000--2500$

$-3500--3000$

$-4000--3500$

$-4500--4000$

$-5000--4500$

$-5500--5000$

Below -5500

Undefined Valus

Figure 3. Model extent and bathymetry. 


\section{Numerical Modelling of Waves for the 1991 Cyclone}

\subsection{The Model}

The regional wave model set up by RHDHV based on the MIKE21 Spectral Wave (SW) Model was used to simulate the generation and propagation of cyclone waves. The fully spectral formulation was used with in-stationary time formulation. The higher order numerical scheme was used to improve accuracy in model results. Wave diffraction, wave breaking, bottom friction and white capping were included in the model simulations. Quadruplet wave interaction was included together with the JONSWAP fetch growth empirical spectral formulation.

\subsection{Methodology}

The cyclone wave model was driven by the wind and pressure fields as shown in Figure 2. A constant water level of $+2.6 \mathrm{mCD}$ was used in the model. The model simulations covered the entire passage of the cyclone across the Bay of Bengal.

\subsection{Model Validation}

Information on the maximum significant wave heights during the 1991 Cyclone were obtained from public domain through a literature search. No suitable measured wave data was found from the literature search. Therefore, model validation was relied on previously carried out numerical modelling studies by various authors as in Table 4 .

Previous numerical modelling of the 1991 Cyclone was carried out by [11] using the SWAN Model (developed by Technical University of Delft), by [15] using the MIKE21 Spectral Wave Model (developed by DHI) and by [16] also using the SWAN Model. The maximum significant wave heights from these studies are summarised in Table 4 and are compared with the values calculated in this study at several locations along the south-east coastal waters of Bangladesh.

Table 4. Maximum significant wave height $\left(H_{m 0}, m\right)$ comparison.

\begin{tabular}{llllll}
\hline \multirow{2}{*}{ Sources } & \multicolumn{2}{l}{ Locations } & & & \\
\cline { 2 - 6 } & Hatia Island & Sandwip Island & Chittagong & Anwara & Kutubdia Island \\
\hline Hendri [11] & - & - & 5.50 & 5.60 & 5.60 \\
BUET [15] & 4.25 & 4.75 & 5.25 & 5.25 & 5.75 \\
George Mason University [16] & 4.00 & 4.50 & 5.00 & 5.00 & 6.00 \\
Study results & 3.25 & 4.50 & 5.25 & 5.00 & 6.00 \\
\hline
\end{tabular}

The study appears to under-predict the maximum significant wave height at the Hatia Island when comparing with the other studies. However, the maximum significant wave heights at other locations were broadly similar to those from $[11,15,16]$. Therefore, it is concluded that the latest model provides a good representation of wave conditions across the Bay of Bengal during the 1991 cyclone.

\subsection{Model Results and Discussions}

The model results for the 1991 Cyclone indicate that the maximum hindcast significant wave height $\left(\mathrm{H}_{\mathrm{m} 0}\right)$ of approximately $14.7 \mathrm{~m}$ (with associated peak wave period of $13.8 \mathrm{~s}$ ) occurred at location of $90.7^{\circ} \mathrm{E}, 20.6^{\circ} \mathrm{N}$ on 29 April 1991 11:00:00. The two-dimensional distribution of wave height contours superimposed by wave directional vectors is shown in Figure 4 for this time-step. The figure indicates that the maximum wave heights were generated near the southeastern coastal waters of Bangladesh. The temporal variation in significant wave height and peak wave period at this location is shown in Figure 5. The figure indicates that significant wave heights higher than $10 \mathrm{~m}$ were sustained for approximately 5 hours and wave heights higher than $12 \mathrm{~m}$ were sustained for approximately 3.5 hours.

Further statistical analyses of model results were carried out using the MIKE21 Tool to derive mean and maximum wave conditions over the Bay of Bengal. The maximum wave heights over the model domain are shown in Figure 6. Figure 7 shows the locations and bed levels of selected points (points 1 to 29) along the cyclone track where model results were also extracted. Model results at these selected locations are shown in Figure 8 and Figure 9.

The modelling results for the 1991 Cyclone indicate that it was a major event that generated waves up to $14.7 \mathrm{~m}$ at the height of the storm. The storm took a north-easterly track and travelled into the south-east coastal waters of Bangladesh resulting in high waves off the coast. The north-easterly passage of the cyclone meant that the impact on the Indian coast and the south-western coast of Bangladesh was limited.

The results indicate that the impact of the cyclone was greatest along the coast approximately $80 \mathrm{~km}$ south-east of the landfall site and that the zone of major impact extended over a distance of approximately $250 \mathrm{~km}$ south-east of the landfall location. 


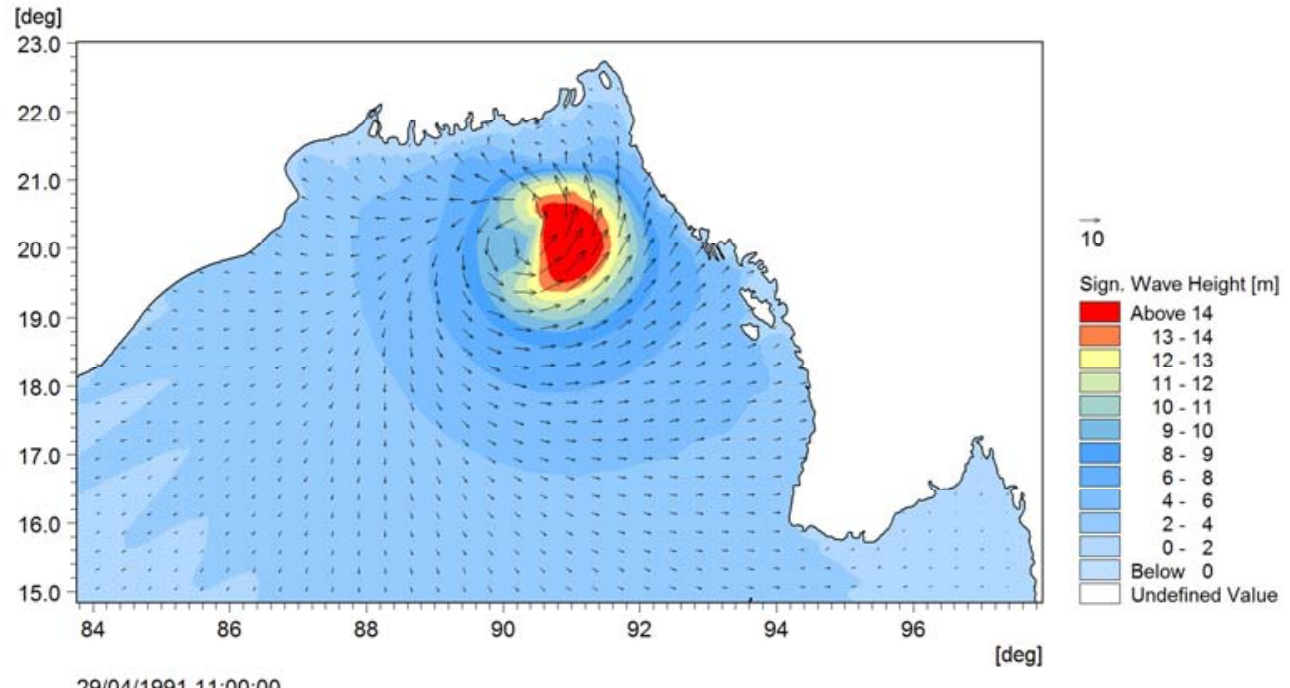

Figure 4. Significant wave heights $\left(H_{m 0}\right)$ of the 1991 Cyclone on 29/04/1991 11:00:00.

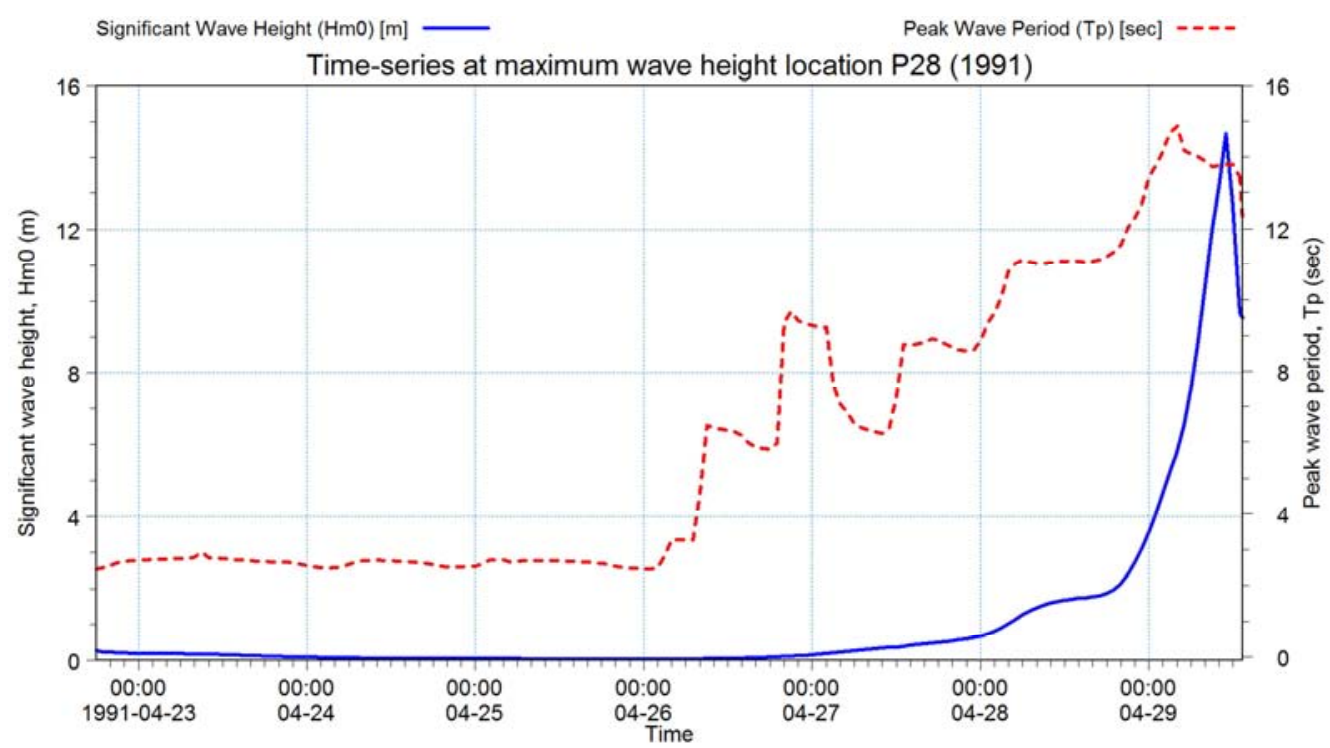

Figure 5. Time-series of waves over the entire duration of the $1991 \mathrm{Cyclone}$ at point 28 [90.7 ${ }^{\circ} \mathrm{E}, 20.6^{\circ} \mathrm{N}, 93 \mathrm{~m}$ depth].

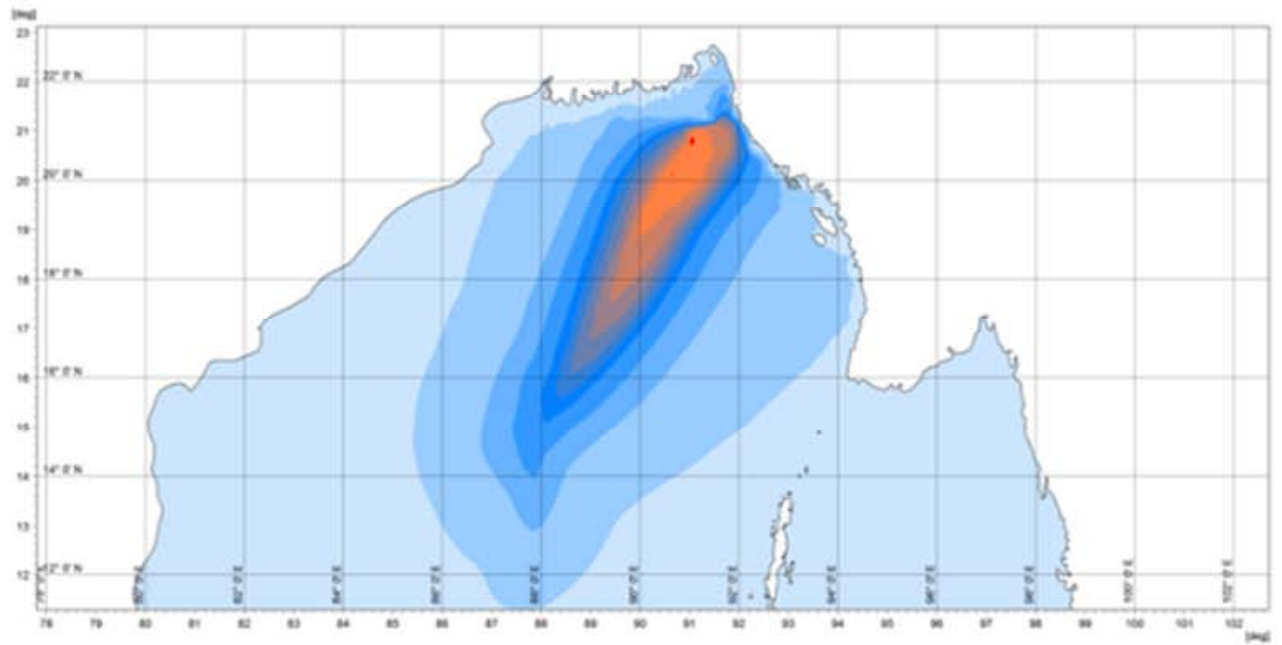

Maximum Sign. Wave Height [m]
Above 16.75
$15.50-16.75$
$14.50-15.50$
$13.50-14.50$
$12.50-13.50$
$11.50-12.50$
$10.50-11.50$
$8.50-10.50$
$6.50-8.50$
$3.50-6.50$
$0.00-3.50$
Below 0.00
Undefined Value

Figure 6. Maximum significant wave height $\left(H_{m 0}\right)$ over the entire duration of the 1991 Cyclone. 


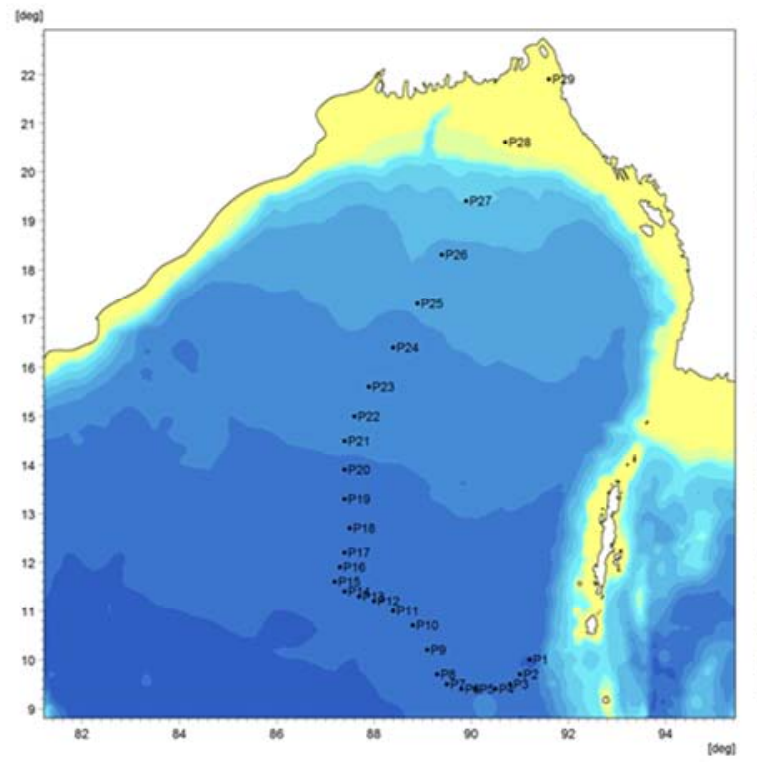

Bathymetry [mCD]

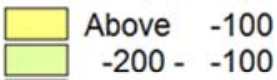

$-300--200$

$-400--300$

$-500--400$

$-1000--500$

$-1500--1000$

$-2000--1500$

$-2500--2000$

$-3000--2500$

$-3500--3000$

$-4000--3500$

$-4500--4000$

$-5000--4500$

$-5500--5000$

Below -5500

Undefined Valus

Figure 7. Output points along the track of the 1991 Cyclone.

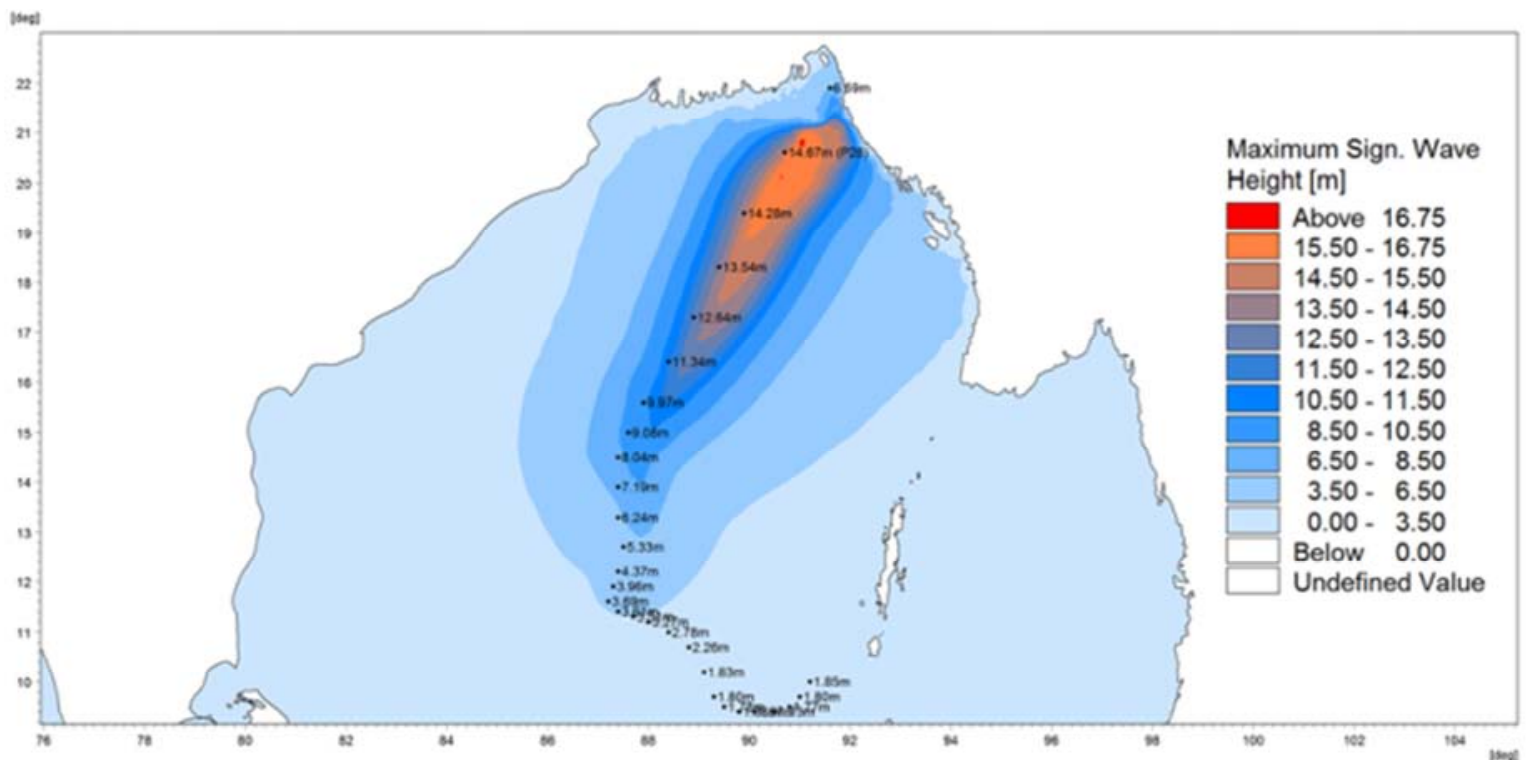

Figure 8. Maximum significant wave heights $\left(H_{m 0}\right)$ at various points along the track of the 1991 Cyclone.

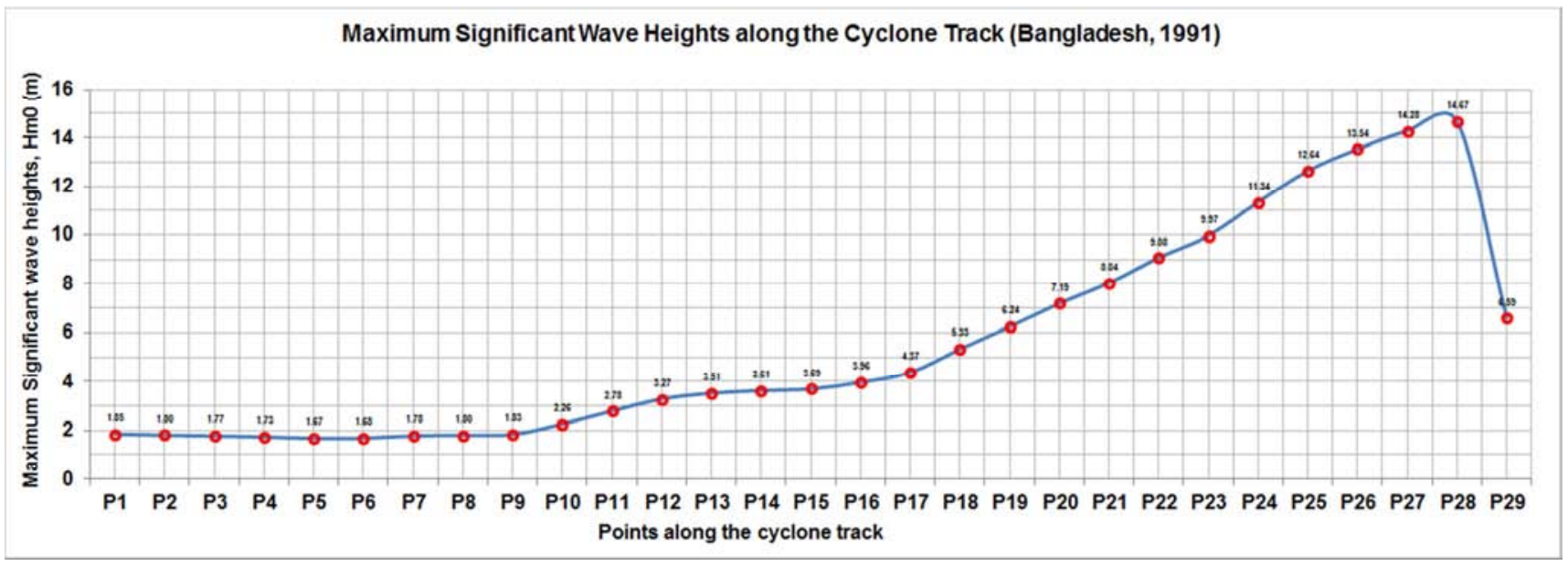

Figure 9. Graphical presentation of maximum significant wave heights $\left(H_{m 0}\right)$ at various points along the track of the 1991 Cyclone. 


\section{Findings and Conclusions}

This article illustrates how a wave model can be used to simulate the impacts of cyclones on coastal developments and facilities. The findings from the modelling study are summarised below:

(1) The maximum significant wave height of approximately $14.7 \mathrm{~m}$ (with associated peak wave period of 13.8s) was generated off the south east coastal areas of Bangladesh;

(2) Significant wave heights higher than $10 \mathrm{~m}$ were sustained for duration of about 5 hours and wave heights higher than $12 \mathrm{~m}$ were sustained for duration of about 3.5 hours;

(3) The cyclone generated high waves in the south-east coastal waters of Bangladesh. The impact on the Indian coast and the south-western coast of Bangladesh was limited;

(4) The impact of the cyclone was greatest along the coast approximately $80 \mathrm{~km}$ south-east of the landfall site. The zone of major impact extended approximately $250 \mathrm{~km}$ south-east of the landfall location.

The methodology described in this paper for modelling cyclone waves in the Bay of Bengal could also be applied to other sites around the world that are affected by this type of event.

\section{Acknowledgements}

The author would like to thank Royal HaskoningDHV (an independent, international engineering and project management consultancy company, www.royalhaskoningdhv.com) for giving permission to publish this paper. Special thanks to Mr. Alec Sleigh (Technical Director, Maritime Sector of Royal HaskoningDHV UK) who carried out an internal review of the paper. The author would also like to thank the external reviewer (s) who provided valuable comments to improve the paper.

\section{References}

[1] Wikipedia (2018a). Effects of tropical cyclones, https://en.wikipedia.org/wiki/Effects_of_tropical_cyclones.

[2] Ubydul Haque, Masahiro Hashizume, Korine N Kolivras, Hans J Overgaard, Bivash Das, and Taro Yamamotoa (2012). Reduced death rates from cyclones in Bangladesh: what more needs to be done? Bulletin of the World Health Organization, 2012 Feb 1; 90 (2): 150-156, PMCID: PMC3302549, published online 2011 Oct 24. doi: 10.2471/BLT.11.088302.

[3] Wikipedia (2018b).

https://en.wikipedia.org/wiki/1970_Bhola_cyclone

[4] Wikipedia (2018c).1991 Bangladesh Cyclone, https://en.wikipedia.org/wiki/1991_Bangladesh_cyclone.
[5] Gray, W. M. (1968). Global view of the origin of tropical disturbances and storms. Mon. Weather Rev. 96: 669-700.

[6] IMD (2013). India Meteorological Department (IMD) under the Ministry of Earth Sciences of the Government of India. Mausam Bhawan, Lodi Road, New Delhi - 110003, India. http://www.imd.gov.in.

[7] Shore Protection Manual (1984). Shore Protection Manual, Volume I, Figure 3-13, page 3-29, 4th edition, 1984. US Army Corps of Engineers, Washington, DC 20314.

[8] JTWC (2018). The Joint Typhoon Warning Center (JTWC), the U.S. Department of Defence Agency, http://www.usno.navy.mil/JTWC.

[9] Khan, S. R. (Unknown). Cyclone hazard in Bangladesh, Appendix - Background information on the storm surge modelling, revised by Michiel Damen, ITC. http://www.adpc.net/casita/case studies/coastal\%20hazard\%2 0assessment/modelling\%20cyclone\%20hazard\%20in\%20bang ladesh/background_information_on_the_storm_surge_modelli ng.pdf.

[10] Hoque, M. M. (1991). Field study and Investigation on the damage caused by cyclones in Bangladesh: a report on the April 1991 cyclone; Cyclone damage in Bangladesh, report on field study and investigations on the damage caused by the cyclone in Bangladesh in 29 - 30 April 1991, United Nations Centre for Regional Development, Nagoya, Japan, 1991, pp. 75 .

[11] Hendri, H., Lee, H. S. and Yamashita, T. (2013). Storm surge, wave and inundation simulation in the Bay of Bengal, Proceedings of the 7th International Conference on Asian and Pacific Coasts (APAC 2013), Bali, Indonesia, September 2426, 2013.

[12] DHI (2016a). MIKE21 Toolbox User Guide, DK-2970, Hørsholm, Denmark, 2016.

[13] DHI (2016b). MIKE21 Spectral Wave Model User Guide, DK-2970, Hørsholm, Denmark, 2016. C-Map (2014). JEPPESEN Commercial Marine, Hovlandsveien 52, Egersund, Postal Code 4370, Norway, 2014, available online at http://www.jeppesen.com/index.jsp.

[14] Islam, M. S. (2015). Modelling the effects of cyclonic storm surge and wave action on selected coastal embankments, PhD Thesis, Bangladesh University of Engineering \& Technology (BUET), Dhaka, 2015.

[15] Deb, M., Ferreira, C (Unknown). Storm surge modelling in the Bay of Bengal, Department of Civil, Environmental \& Infrastructure Engineering, Volgenau School of Engineering, George Mason University.

[16] Sarker, M. A. and Sleigh, A. J. (2015). Cyclone and tsunami hazards in the Arabian Sea - A numerical modelling case study by Royal HaskoningDHV. Journal of Shipping and Ocean Engineering, Volume 5, Number 5, Sep-Oct 2015, pages 242-254, DOI 10.17265/2159-5879/2015.05.003, USA.

[17] Sarker, M. A. (2016). Cyclone hazards in the Arabian Sea - A numerical modelling case study of Cyclone Nilofar. Water and Environment Journal of CIWEM, Nov 2016, doi: 10.1111/wej.12214, England. 